\title{
Respiratory allergy in laboratory animal workers: a retrospective cohort study using pre-employment screening data
}

Hanneke Kruize, Wendel Post, Dick Heederik, Ben Martens, Albert Hollander, Erik van der Beek

\begin{abstract}
Objectives-To study the role of exposure, atopy, and smoking in the development of laboratory animal allergy (LAA) in a retrospective cohort study.

Methods-Between 1977 and 1993, 225 people received a pre-employment screening when they started $a$ job at a Dutch research institute where they were going to work with laboratory animals. After active follow up 136 of them (60.4\%) could be traced and were sent a questionnaire with extensive questions on allergic symptoms, smoking habits, and job history. 122 people $(89.7 \%)$ sent back a completed questionnaire. Those who were accepted for $a$ job at the institute and did not have allergic symptoms at the start of the job were selected as cohort members. After selecting people with complete data on start and end date of jobs, exposure intensity, atopy, and smoking, the cohort consisted of 99 people with an average time of follow up of 9.7 years. LAA was defined as a positive response to a set of questions in the questionnaire. The mean number of hours a week a person was exposed to laboratory animals at entry of the cohort was used as a surrogate for exposure, and was divided into four categories.
\end{abstract}

Results-19 cohort members (19.2\%) reported LAA. More people with asthmatic symptoms were found in the high exposure categories. More atopic than nonatopic people reported asthmatic symptoms $(13 \% v 6 \%)$. The mean time until development of symptoms of LAA was about 109 months in non-atopic people $(n=9)$, and 45 months in atopic people $(n=10)$ ( $t$ test; $P<0.05)$. Time until development of symptoms of LAA was shorter at a higher intensity of exposure, except for those exposed for less than two hours a week. A proportional hazard regression analysis showed that exposure and atopy were significant determinants of LAA. An increased relative risk (RR) was found for non-atopic people exposed to laboratory animal allergens for more than two hours a week. Atopic people had an even higher risk when exposed to laboratory animals for more than two hours a week (RR above 7.3). Sex, smoking, and age were not risk factors. More atopic than non-atopic people were absent from work or transferred because of allergies. Conclusions-This study showed that exposure and atopy are significant predictors of LAA and that the risk of developing LAA remained present for a much longer period (>3 y) than considered before.

(Occup Environ Med 1997;54:830-835)

Keywords: atopy; laboratory animals; allergy

People who work with laboratory animals are at risk of developing an allergy to the animals they work with. Prevalence rates of $10 \%-30 \%$ have been found, and give an impression of the magnitude of the health risks. ${ }^{12}$ Urinary proteins of laboratory animals are the cause of laboratory animal allergy (LAA) ${ }^{1{ }^{2}}$ Mild symptoms of LAA are rhinitis, and skin and eye reactions. ${ }^{134}$ Asthma is a more severe form that develops in about $17 \%-71 \%$ of cases of LAA. ${ }^{1}$ There are some suggestions that most cases develop LAA two to three years from initial exposure to the allergen. ${ }^{12}$ However, the evidence for this is limited and is mainly based on clinical data. No unbiased estimates of time till sensitisation are available from well designed epidemiological studies.

Allergen concentrations are known to vary considerably, and depend on stock density, tasks performed, ventilation rates, ${ }^{5}$ cage design, bedding type, air filtration, and humidity. ${ }^{2}$ Despite these findings, few studies focused on the relation between exposure intensity and duration and development of LAA. Recent findings from a cross sectional study performed suggest that work related symptoms are related to exposure intensity (expressed either in terms of dust or aeroallergen concentrations) at the time of onset of symptoms of LAA. ${ }^{6}$ Generally, crude proxies have been used to characterise exposure to allergens. In one cross sectional study the degree of exposure to animals had a positive and significant association with the presence of LAA, but duration of employment was not related to LAA. ${ }^{7}$ Renström et al ${ }^{\beta}$ examined the differences for several response variables in an exposed and a matched non-exposed group (36 pairs) which were sampled out of a large group of laboratory animal workers. After two years of follow up no clear differences were found between the two groups in incidence of LAA, specific IgE, and atopy. Work related allergic symptoms were 
reported more often at follow up. Several studies have shown that atopic people are at higher risk of developing LAA. ${ }^{1679}$ One study showed that people with atopy develop LAA earlier than those without. ${ }^{3}$ Furthermore it has been mentioned that atopic people are more likely to develop the allergy in a more severe form. ${ }^{146}$ Smoking is also suggested to be related to LAA, possibly by increasing mucosal transport of allergens, but evidence is not conclusive. ${ }^{1}$ Age and sex are said to be effect modifiers in the development of occupational asthma as well, but have hardly been studied in relation to LAA.

Most studies published have cross sectional designs and potentially have several forms of bias. A recently conducted cross sectional study in laboratory animal workers showed that a clear exposure-response relation between exposure to urinary proteins and allergic sensitisation could only be found in workers employed for less than four years, probably because of the healthy worker effect. ${ }^{10}$ Quantitative unbiased estimates of these factors are therefore not available. Moreover, in cohort studies of laboratory animal workers there was a shorter period of follow up than the time untill sensitisation. ${ }^{3} 78$

This cohort was followed up for longer than most other cohorts of laboratory animal workers and all participants were free of symptoms at the start of follow up. The time after which symptoms of LAA developed was known and this allowed calculation of incident density ratios (IDRs). The primary aim of this study was to determine the effect of exposure intensity on the development of LAA and the role of other variables, such as atopy, smoking, calendar period, sex, and age.

\section{Methods}

Between 1977 and 1993, 225 people underwent pre-employment screening for a job with laboratory animals at three parts of a Dutch research institute. Pre-employment screening was done by the Allergy Centre of Utrecht and consisted of a full respiratory and allergy anamnesis. Skin prick tests to house dust mite, pollen, and several animals, were performed at the Allergy Centre. All participants were tested for cats, dogs, or animals to which they had been exposed. In 1993 and 1994 home addresses of these people were traced. Personnel records of the Dutch Research Institute were used, as well as registries of the pension fund. For the remaining cases, a CD-ROM telephone guide was consulted within $30 \mathrm{~km}$ of the laboratories. For 136 people (60.4\%) addresses were found and they were sent a questionnaire with extensive questions on work related allergic symptoms, smoking habits, and job history. One hundred and twenty two people $(89.7 \%)$ returned the questionnaire. People with allergic symptoms before getting the job, and those who finally did not get a job at the institute, were excluded from the cohort. Traced people with incomplete data on their job history (date starting or ending jobs), exposure, atopy, or smoking were excluded from further analyses. Therefore the cohort used in the analyses included 99 symptom free participants $(72.8 \%)$. The date a person started a job at the institute was defined as cohort entry date.

\section{ALLERGIC SYMPTOMS}

The self administered questionnaire contained questions about personal history of allergic symptoms to common allergens, history of allergic symptoms to laboratory animals, and intensity of contact with laboratory animals, and has been used earlier in a study on LAA. ${ }^{10}$ Allergic symptoms due to working with laboratory animals were defined as the presence of allergy during working hours, or after contact with laboratory animals (Do you have any of the following symptoms during work, after contact with laboratory animals (please specify animal species)?) Self reported allergic symptoms were divided into four groups: nasal symptoms, defined as sneezing and runny nose (production of nasal secretions); skin symptoms defined as itching or red skin; eye symptoms, defined as itching or smarting eyes; and asthma, defined as presence of shortness of breath and wheezing. The questionnaire used came from another study in laboratory animal workers. ${ }^{10} 11$ The sensitisation period was defined as the period between the first exposure to laboratory animals and the first occurrence of symptoms of LAA.

\section{EXPOSURE}

As a surrogate for exposure intensity the mean number of hours a week a person was exposed to laboratory animals at baseline was used. Exposure intensity was divided into four categories in most analyses with roughly similar numbers of participants. The exposure intensity categories were: $<2$ hours a week, $2-<15$ hours a week, 15-<38 hours a week, and $\geqslant 38$ hours a week on average. Potential exposure before cohort entry was omitted. Some participants had been exposed during training, but the average exposure duration during training was less than three months.

\section{OTHER VARIABLES}

People were atopic if they had a positive skin prick test at baseline to house dust mite, pollen, or an animal (cat, dog, or other animal they had been exposed to outside the workplace). A recently published paper showed that atopy defined on the basis of atopic sensitisation to other animals was the best predictor of LAA. ${ }^{11}$ Smoking at baseline was used in the analyses. No distinction was made between smoking cigarettes, cigars, or a pipe. Three calendar periods for those entering the cohort were distinguished with baseline date: 1973-80, 1981-6 and 1987-94.

\section{ANALYSES}

Statistical analyses were performed with Statistical Analyses Software (SAS). Mean and median sensitisation periods were calculated with Proc Univariate. Incidence density rates were calculated by dividing the number of cases of LAA by the sum of person-years for each person from the entry date to the cohort 
until the end of the follow up (1993-4), or until the first symptoms of LAA were reported. Survival analyses were performed with proportional hazard techniques.

\section{Results}

Of the 225 people who underwent a preemployment medical, 89 (39.6\%) could not be traced and 136 were sent a questionnaire. Eleven $(8.1 \%)$ reported personal reasons for refusing participation and three $(2.2 \%)$ had died. Of the 122 people who completed the questionnaire, 13 were excluded from the cohort because they reported symptoms of LAA at the pre-employment medical ${ }^{9}$ or finally did not start working at the institute. ${ }^{4}$ Nine people with incomplete data on when starting or ending jobs, exposure intensity, atopy, or smoking were also excluded from further analyses. This resulted in a cohort of 99 people $(72.8 \%)$. Since baseline data were available for all 225, the prevalence of atopy could be studied in cohort members and those who were not included in the cohort. Prevalence of atopy did not differ significantly between the two groups $(31.2 \%(31 / 99) v 40.2(49 / 122)$ respectively, Fisher's exact test, $\mathrm{P}>0.15)$. Similar inclusion criteria were applied in this comparison.

ALLERGIC SYMPTOMS

Table 1 shows general characteristics of the cohort. Nineteen people reported LAA, resulting in a incidence of LAA of $19.2 \%$. The incidence in the first year of employment was $4.0 \%$ - that is, four of the LAA cases. Seventeen of the LAA cases $(89.5 \%)$ reported an allergy to rats, seven (36.8\%) to mice, four $(21.1 \%)$ to guinea pigs, and three $(15.8 \%)$ to rabbits (table 1). Most cases reported nose or skin symptoms. Asthmatic symptoms were reported by $42.1 \%$ of the LAA cases. Asthmatic symptoms were always, except for one subject, accompanied by other symptoms. People with asthmatic symptoms were only found among people who worked with laboratory animals for more than two hours a week on average. More atopic than non-atopic people developed asthmatic symptoms $(13 \% v 6 \%)$.

\section{SENSITISATION PERIOD}

The mean sensitisation period for non-atopic people with LAA ( $n=9)$ was about 109 months and differed significantly from the mean sensi-

Table 1 General descriptive information on 99 laboratory animal workers

\begin{tabular}{llc}
\hline & $n$ & $\%$ \\
\hline Participants & 99 & 100 \\
Female workers & 44 & 44.4 \\
Atopic workers & 31 & 31.3 \\
Smokers at cohort entry & 47 & 47.5 \\
LAA & 19 & 19.2 \\
Rat allergy & 17 & 17.3 \\
Mouse allergy & 7 & 7.1 \\
Guinea pig allergy $^{\star}$ & 4 & 4.1 \\
Rabbit allergy $^{\star}$ & 3 & 3.1 \\
Work related allergy symptoms $^{\star}:$ & 14 & 14.3 \\
Rhinitis $^{\star}$ & 8 & 8.2 \\
Eysthma $^{\star}$ & 11 & 11.2 \\
Skin $^{\star}$ & 15 & 15.3 \\
Age at cohort entry (mean (range)) & 25 & $16-44$ \\
\hline
\end{tabular}

${ }^{\star_{n}}=98$ due to missing information in one of the questionnaires. tisation period of atopic people with LAA $(n=10)$, which was about 45 months (KruskalWallis, $P<0.05)$. The mean sensitisation period decreased with increasing exposure intensity, except for the lowest exposure category (table 2). The two highest exposed categories (exposure intensity $\geqslant 15$ hours a week) had a significantly shorter mean sensitisation period than the two categories with the lowest exposure (exposure intensity $<15$ hours a week; Kruskal Wallis test, $P<0.05$ ). Thirteen of the 23 cases of LAA were referred to the Allergy Centre of Utrecht by the Occupational Health Service because these workers developed symptoms of LAA. For these cases, the difference between the onset of symptoms of LAA reported by questionnaire and clinically confirmed LAA reported in the medical files was two years maximum, with a Pearson correlation of $>0.90$ $(P<0.05)$.

INCIDENCE DENSITY RATES

The overall IDR was 1.97 cases per 100 person-years (table 3). The IDR increased with increasing exposure intensity. The IDR for atopic people was more than three times higher than for non-atopic people. Smokers had a higher IDR than non-smokers. Men seemed to have a higher IDR than women. The risk of developing LAA seemed to increase with time, as indicated by the IDR by calendar period.

\section{SURVIVAL ANALYSIS}

Table 4 shows the characteristics of the exposure intensity categories. An analysis with exposure intensity, atopy, smoking at baseline, calendar period, sex, and age in one model,

Table 2 Mean and median time until development of $L A A$ symptoms (in month) for 19 laboratory animal workers with self reported $L A A$

\begin{tabular}{|c|c|c|c|c|}
\hline & $\begin{array}{l}L A A \text { cases } \\
(n)\end{array}$ & Mean & Median & Range \\
\hline All cases & 19 & 76 & 63 & $<1-270$ \\
\hline Non-atopic cases & 9 & 109 & 98 & $7-270$ \\
\hline Atopic cases & 10 & 45 & 27 & $<1-117$ \\
\hline $\begin{array}{l}\text { Exposure }<2 \mathrm{~h} / \text { week } \\
2 \leqslant \text { Exposure }<15\end{array}$ & 2 & 83 & 83 & $30-36$ \\
\hline $\begin{array}{c}\mathrm{h} / \text { week } \\
15 \leqslant \text { Exposure }<38\end{array}$ & 6 & 133 & 113 & $83-270$ \\
\hline $\mathrm{h} /$ week & 7 & 58 & 56 & $1-192$ \\
\hline Exposure $\geqslant 38 \mathrm{~h} /$ week & 4 & 16 & 14 & $<1-36$ \\
\hline
\end{tabular}

Table 3 Number of LAA cases, sum of person-years of follow up, and incidence density ratios (IDRs); overall, by atopic status, sex, exposure, and smoking at cohort entry

\begin{tabular}{|c|c|c|c|}
\hline & $\begin{array}{l}L A A \\
\text { cases (n) }\end{array}$ & $\begin{array}{l}\text { Sum of } \\
\text { person-years }\end{array}$ & $\begin{array}{l}\text { IDR cases } / 100 \\
\text { person-years }\end{array}$ \\
\hline All cases & 19 & 964.6 & 1.97 \\
\hline Non-atopic cases & 9 & 722.6 & 1.25 \\
\hline Atopic cases & 10 & 242.0 & 4.13 \\
\hline $\begin{array}{l}\text { Exposure }<2 \mathrm{~h} / \text { week } \\
2 \leqslant \text { Exposure }<15\end{array}$ & 2 & 232.2 & 0.86 \\
\hline $\begin{array}{l}\mathrm{h} / \text { week } \\
15 \leqslant \text { Exposure }<38\end{array}$ & 6 & 210.3 & 2.85 \\
\hline $\begin{array}{l}\mathrm{h} / \text { week } \\
\text { Exposure } \geqslant 35\end{array}$ & 7 & 309.8 & 2.26 \\
\hline $\mathrm{h} /$ week & 4 & 212.3 & 1.88 \\
\hline Non-smokers & 10 & 542.8 & 1.84 \\
\hline Smokers & 9 & 421.8 & 2.13 \\
\hline Men & 10 & 496.0 & 2.02 \\
\hline Women & 9 & 469.0 & 1.92 \\
\hline $1973-80$ & 7 & 461.6 & 1.52 \\
\hline $1981-6$ & 9 & 411.8 & 2.19 \\
\hline $1987-94$ & 3 & 91.3 & 3.29 \\
\hline
\end{tabular}


Table 4 Risk factors of $L A A$ and LAA related end points by exposure intensity categories for 99 laboratory animal workers

\begin{tabular}{lclll}
\hline & $\begin{array}{c}\text { Exposure }<2 \\
\text { h/week }\end{array}$ & $\begin{array}{l}2 \leqslant \text { Exposure } \\
<15 \text { h/week }\end{array}$ & $\begin{array}{l}15 \leqslant \text { Exposure } \\
<38 \text { h/week }\end{array}$ & $\begin{array}{l}\text { Exposure } \geqslant 38 \\
\text { h/week }\end{array}$ \\
\hline Total in category & 25 & 25 & 25 & 24 \\
LAA cases & $2(8)$ & $6(24)$ & $7(28)$ & $4(17)$ \\
Asthma & $0(0)$ & $2(8)$ & $3(12)$ & $3(13)$ \\
Atopy & $11(44)$ & $6(24)$ & $7(28)$ & $7(29)$ \\
Women & $6(24)$ & $11(44)$ & $12(48)$ & $15(63)$ \\
Smoking at baseline & $9(36)$ & $12(48)$ & $13(52)$ & $13(54)$ \\
Absent from work due to & $0(0)$ & $0(0)$ & $3(13)$ & $3(13)$ \\
$\quad \begin{array}{l}\text { symptoms } \\
\text { Transferred to another job* }\end{array}$ & $0(0)$ & $1(4)$ & $3(13)$ & $4(17)$ \\
Age (mean (range)) & $27(17-24)$ & $30(20-44)$ & $23(17-42)$ & $20(16-32)$ \\
\hline
\end{tabular}

${ }^{*_{n}}=98$ due to missing information in one of the questionnaires.

Table 5 Results from simple univariate proportional hazard regression analyses of symptoms of $L A A$ by exposure and potential confounders in 99 laboratory animal workers

\begin{tabular}{|c|c|c|c|}
\hline & $L A A / n$ & $R R$ & $(95 \% C I)$ \\
\hline Exposure $<2$ & $2 / 25$ & 1.0 & - \\
\hline $\begin{array}{l}2 \leqslant \text { Exposure }<15 \mathrm{~h} / \text { week } \\
15 \leqslant \text { Exposure }<38\end{array}$ & $6 / 6$ & $5.3^{\star}$ & (1.0 to 27.6 ) \\
\hline $\mathrm{h} /$ week & $7 / 25$ & $5.1 t$ & $(0.9$ to 28.0$)$ \\
\hline Exposure $\geqslant 38 \mathrm{~h} /$ week & $4 / 24$ & 3.6 & (0.6 to 21.5$)$ \\
\hline Non-atopic cases & $9 / 68$ & 1.0 & - \\
\hline Atopic cases & $10 / 31$ & $4.2^{\star}$ & (1.5 to 11.3$)$ \\
\hline Non-smokers & $10 / 52$ & 1.0 & - \\
\hline Smokers & $9 / 47$ & 0.8 & (0.3 to 2.1 ) \\
\hline $1973-80$ & $7 / 35$ & 1.0 & - \\
\hline $1981-6$ & $9 / 38$ & 1.6 & (0.5 to 4.6$)$ \\
\hline $1987-94$ & $3 / 26$ & 1.8 & $(0.4$ to 8.3$)$ \\
\hline
\end{tabular}

$\star \mathrm{P}<0.05 ;+\mathrm{P}<0.10$

showed that sex and age were not significantly related to $L A A$, with relative risks (RR) of $0.8(\mathrm{P}=0.71)$ and $1.0(\mathrm{P}=0.49)$ respectively Therefore age and sex were excluded from subsequent models. A weak period effect seemed present. The risk of developing LAA was, however, non-significantly increased in people who started their job at the institute at a later calendar date.

Table 5 shows the results of the remaining model. The RRs for the four exposure categories were $1.0,5.3,5.1$, and 3.6 respectively. The relative risk for the category with an exposure intensity between two and 15 hours a week was significant, and the RR for the category with an exposure intensity between 15 and 38 hours a week was of borderline significance. When these four exposure intensity categories were rearranged into two categories, a non-exposed category (exposure intensity $<15$ hours a week) and an exposed category (exposure intensity $\geqslant 15$ hours a week) a corrected RR of 1.5 was found $(P=0.47)$. Although most atopic people

Table 6 Multiple proportional hazard regression of LAA on exposure corrected for atopy (only first model) and smoking, for the whole population and stratified by atopy in 99 laboratory animal workers

\begin{tabular}{|c|c|c|c|c|c|c|}
\hline & \multicolumn{2}{|c|}{ All workers } & \multicolumn{2}{|c|}{ Non-atopic cases } & \multicolumn{2}{|c|}{ Atopic cases } \\
\hline & $R R$ & $(95 \% C I)$ & $R R$ & $(95 \% C I)$ & $R R$ & $(95 \% C I$ \\
\hline $\begin{array}{l}\text { Reference category } \\
2 \leqslant \text { Exposure }<15\end{array}$ & $\begin{array}{l}1.0 \\
5.3+\end{array}$ & - & 1.0 & - & 1.0 & - \\
\hline $\begin{array}{l}h / \text { week } \\
15 \leqslant \text { Exposure }<38\end{array}$ & $5.1 \dagger$ & (1.0 to 25.9 ) & 2.5 & $(0.3$ to 24.5$)$ & $8.0 \dagger$ & (0.8 to 79.5$)$ \\
\hline h/week & & (0.9 to 22.6 ) & 2.5 & (0.2 to 24.8 ) & $7.3 t$ & (0.7 to 72.5 ) \\
\hline Exposure $\geqslant 38 \mathrm{~h} /$ week & 3.6 & $(0.5$ to 17.6$)$ & 1.1 & (0.1 to 18.5$)$ & $8.3 \dagger$ & (0.8 to 85.7$)$ \\
\hline Smokers & 0.8 & $(0.3$ to 2.2$)$ & 1.6 & $(0.4$ to 6.9$)$ & $0.6^{\circ}$ & $(0.2$ to 2.1$)$ \\
\hline Atopic cases & $3.8^{\star}$ & - & - & - & - & - \\
\hline
\end{tabular}

$\star \mathrm{P}<0.05,+\mathrm{P}<0.10$ were in the non-exposed category, the RR was still higher in the exposed category.

Survival analysis assumes proportionality of survival curves for all exposure categories. This implies that the curves of the four exposure categories should not cross. In most cases these assumptions were not violated although after about 100 months of follow up curves crossed in some analyses for some exposure categories. An analysis limited to 100 months of follow up did not result in different risk estimates.

People with atopy were at greater risk of developing LAA. A relative risk of $4.2(\mathrm{P}<0.05$, $95 \%$ confidence interval ( $95 \% \mathrm{CI}) 1.5$ to 11.3 ) was found for atopy, corrected for exposure intensity, calendar period, and smoking (table 5). Table 6 shows a separate analysis for atopic and non-atopic people. Atopic people seemed to have an increased risk of developing LAA when exposed. The RRs for the three exposure intensities were 8.0, 7.3, and 8.3 respectively. For non-atopic people, the pattern was about the same as for atopic people; but RRs were lower.

When participants with an exposure intensity of less than 15 hours a week were compared with participants with a higher exposure intensity, a difference was found in the number of people who reported absence from work because of allergic symptoms $(0 \% v$ $13 \%)$. The proportion of people who were transferred to another task or job because of allergic symptoms also differed among these two categories (respectively $2 \% v 15 \%$ ).

A significant difference in the number of people who were transferred to another task or job because of their symptoms of LAA was also found between atopic and non-atopic people $(16 \%$ v $5 \%$ respectively, $\mathrm{P}<0.10)$. The difference between atopic and non-atopic people in absenteeism from work because of allergic symptoms was small: $10 \% v 5 \%$ respectively.

\section{Discussion}

This study shows that both non-atopic and atopic people seemed to have an increased risk related to exposure intensity when exposed to laboratory animal allergens. Atopic people developed LAA significantly earlier and in more severe forms (asthma) than non-atopic people. The time until development of the first symptoms of LAA was longer than reported in previous studies. ${ }^{12}$ In this study the mean time until development of the first symptoms was 76 months, with a maximum of 270 months. The risk of developing LAA remained present, even after three years of exposure to laboratory animals.

This study had possible selection bias because of loss to follow up, which could be related to LAA or the allergen exposure. Of 225 people who were eligible to participate in this study, 122 completed the questionnaire. Most of the non-response $(86.4 \%)$ occurred because the address was unknown, despite active follow up. Other causes of non-response were a change in name because some women married, and some women were not expected to pay a pension contribution and were therefore not registered by the pension fund. A 
few people had emigrated, particularly researchers. People were also not recorded in the CD-ROM telephone guide. Despite high rates of loss to follow up, selection bias seems unlikely, as a similar prevalence of atopy was found in non-participants and participants. Also, the distribution of men and women was similar in non-participants and participants. Participants and non-participants were evenly distributed over the three cohort entry periods. Although non-response was considerable, the final cohort still consisted of 99 people $(72.8 \%$ of the people who were sent a questionnaire), many participants in comparison with other cohort studies. $^{48}$

People at risk were followed up until the development of LAA. The presence of the first symptoms of LAA was determined by questionnaire. This could have been vulnerable to responder bias. However, a comparison of the value of the self reported information on the time a participant developed the first symptoms of LAA with medical information present at the Allergy Clinic showed that of all 23 cases of LAA, 13 were again seen by the medical specialist (BM) during the follow up period. For all these cases LAA was confirmed clinically by SPT or by serological testing. For these 13 cases, the difference between the time of onset of symptoms reported by questionnaire and reported in the medical files was two years at most and the correlation between the two sources of information was high (Pearson

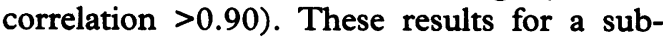
group of cases of LAA suggest that the self reported information was valid for presence and onset of LAA. For 10 cases, no additional information could be found in the records of the Allergy Centre, probably because they were not referred to this clinic by the occupational health service. No cohort members who did not report symptoms in the questionnaire during the follow up were seen at the Allergy Centre after the initial evaluation. Although this cannot be seen as a complete evaluation of the validity of the questionnaire used, it does suggest that recall of symptoms agreed with the clinical evaluation of symptoms made during the follow up and that no over or underreporting occurred. It also suggests that those who developed symptoms during the follow up attributed those correctly to working with laboratory animals. This also implies that the relations reported can most probably not be explained by the presence of recall bias. This also seems unlikely as the relation with atopy in this study is comparable with what is commonly found in the scientific literature..$^{1113}$

The incidence of LAA $(19.2 \%)$ was comparable with figures given in other studies. ${ }^{126}$

The incidence in the first year was already $4.0 \%$. Botham et $a l$ reported a decrease in incidence after two and three years of follow up. However, they did not allow for a reduction of the population at risk after the first year of follow up due to development of LAA in some workers. Those who developed LAA during the first year of follow up are not at risk any more during subsequent years and should be removed from the calculations of risk in the sec- ond and third year. Recalculation from their tables shows a slight increase in incidence in the second and third year of follow up compared with the first year. In our study laboratory animal workers were still at risk after having worked for three years with animals at the institute, although the risk decreased after this period.

In this study an increased risk was found for people exposed to laboratory animals for more than two hours a week. The risk decreased for people exposed for more hours a week.This could probably be explained by a healthy worker effect. The number of people who were transferred to another task or job because of allergic symptoms increased with increasing exposure intensity $(0 \%, 4 \%, 13 \%$, and $17 \%$ respectively). Kibby et al also reported a positive association between exposure intensity and the presence of LAA in their prevalence study (prevalence ratio (PR) $1.75 ; 95 \% \mathrm{CI}, 1.06$ to $\left.2.39 ; \chi^{2}=4.97 ; p=0.03\right)$. In their study exposure intensity was the self reported number of hours a day, days a week, and weeks in six months of contact with laboratory animals.

In our study time until onset of the first symptoms of LAA was shorter at higher intensitirs of exposure, except for the category with lowest exposure. The exception could be explained by the highest number of atopic people in this category and the few cases of LAA in this category. People exposed more intensely developed asthmatic symptoms faster. Exposure intensity was a surrogate for the exposure level. It was self reported in the questionnaire and could therefore be biased. This surrogate of exposure has been used in other studies as well. Results from the study by Hollander $e t a l^{10}$ suggest that this surrogate is strongly correlated with the exposure proxy that performed best in the analysis; the number of hours that a person worked with rats multiplied by the antigen level. Exposure before the first job was not considered extensively because all participants were symptom free at the start of this job.

Atopy seemed to be strongly related to the development of LAA. A significant RR of 4.2 was found for atopy in a multiple regression model with exposure intensity, smoking, and calendar period. In other studies comparable RRs were reported. ${ }^{78}$ In the prospective study of Botham et $a l{ }^{3}$ LAA was defined with questionnaires annually. Their data were confirmed clinically only in a few cases. In that study more non-atopic people developed LAA after two and three years. During the first year $19 \%-43 \%$ of atopic people developed LAA compared with $3 \%-6 \%$ of the non-atopic people, but rates became similar during later years. There were some indications that atopy was an effect modifier. In our study atopic people developed symptoms of LAA earlier than nonatopic people. Atopic people also developed LAA more often than non-atopic people. Atopic people had a higher overall increased risk than non-atopic people after being exposed to laboratory animal allergens. A higher percentage of people with asthmatic symptoms was found among atopic people than nonatopic people. This has been confirmed by a 
few other studies. ${ }^{24612}$ Also more atopic people were absent from work or transferred to another job because of symptoms of LAA. Most atopic people were found in the nonexposed category (exposure intensity $<2$ $\mathrm{h} /$ week). This might be indicative of self selection among the participants. It is also possible that advice of the Allergy Centre, where the pre-employment medicals were performed, was responsible for this result. Unfortunately a detailed comparison of the results of this study with other studies is not possible, because the definition of atopy differs considerably between studies.

Most follow up studies were based on an assumed sensitisation period of about three years. ${ }^{38}$ However, our study results showed on average a longer sensitisation period. This could be the result of survivor bias, due to using a cohort selected by means of a pre-employment screening, and excluding people with symptoms of LAA. Also some other studies reported a longer time until development of the first symptoms of LAA than is generally assumed (Lutsky and Neuman, 1975, Neuman and Lutsky, 1976, Hook et al, 1984). Few studies gave proper estimates of the mean time to sensitisation, because the duration of follow up was too short or the series was of more severely affected patients, which could lead to serious bias. Therefore, these studies were not able to estimate correct or unbiased RRs. Furthermore, it seems justified to suggest that in follow up studies a longer follow up should be considered. More research on deter- minants of the duration of the sensitisation period would be of interest.

1 Hunskaar S, Fosse RT. Allergy to laboratory mice and rats: a review of the pathophysiology, epidemiology and clinical aspects. Lab Anim 1990;24:358-74.

2 Newman Taylor AJ, Gordon S. Laboratory animal and insect allergy. In: Bernstein IL, Chan-Yeung M, Malo J-L Bernstein DI, eds. Asthma in the workplace. New York: Marcel Dekker, 1993:399-414.

3 Botham PA, Davies GE, Teasdale EL. Allergy to laboratory animals: a prospective study of its incidence and of the influence of atopy on its development. $\mathrm{Br} \mathcal{F}$ Ind Med 1987; 44:627-32.

4 Davies GE, Thompson AV, Niewola Z, Burrows GE, Teasdale EL, Bird DJ, Phillips DA. Allergy to laboratory animals: a retrospective and prospective study. $\mathrm{Br} \mathcal{F}$ Ind $\mathrm{Med}$ 1983;40:442-49.

5 Nieuwenhuijsen $M J$, Gordon S, Harris J, Tee RD, Venables KM, Newman Taylor AJ. Determinants of airborne allergen exposure in an animal house. Occup Hyg 1995;1:317-24.

6 Cullinan P, Lowson D, Nieuwenhuijsen MJ, Gordon S, Tee $\mathrm{RD}$, Venables KM, et al. Work related symptoms, sensitisation, and estimated exposure to laboratory rats. Occup Environ Med 1994;51:589-92.

7 Kibby T, Powell G, Cromer J. Allergy to laboratory animals: a prospective and cross-sectional study. $\mathcal{F}$ Occup Med 1989; a prospective.

8 Renström A, Malmberg P, Larsson K, Sundblad BM, Larsson PH. Prospective study of laboratory-animal allergy factors predisposing to sensitization and development of allergic symptoms. Allergy 1994;49:548-52.

9 Venables KM, Upton JL, Hawkins ER, Tee RD, Longbottom JL, Newman Taylor AJ. Smoking, atopy, and laboratory animal allergy. Br F Ind Med 1988;45:667-71.

10 Hollander A, Heederik D, Doekes G. Respiratory allergy to rats: exposure-response relationships in laboratory animal rats: exposure-response relationships in laboratory

11 Hollander A, Doekes G, Heederik D. Cat and dog allergy and total IgE as risk factors of laboratory animal allergy. $f$ and total IgE as risk factors of laborat

12 Sjöstedt L, Willers S, Ørbæk P. A follow-up study of laboratory animal exposed workers: the influence of atopy for the development of occupational asthma. Am $\mathcal{F}$ Ind Med 1993 24:459-69.

13 Das R, Tager IB, Gamsky T, Schenker MB, Royce S, Balmes JR. Atopy and airways reactivity in animal health technicians. A pilot study. F Occup Med 1992;34:53-60. 